\title{
Hidroclimatología local e impactos en el lago Sochagota, Paipa, Boyacá*
}

\author{
Juan Camilo Monroy Ramírez ${ }^{\mathrm{a}}$ - Adriana Janneth Espinosa Ramírez ${ }^{\mathrm{b}}$ - Wilson \\ Alejandro Jiménez Avellac
}

\begin{abstract}
Resumen: el lago Sochagota es un sistema construido que actúa como una laguna de oxidación. Su nivel está regulado, posee afloramiento de agua termomineral y recibe escorrentía de suelos sulfatados ácidos y una porción de agua dulce del río Chicamocha; y descarga en el distrito de riego de Usochicamocha. Al incrementar la concentración de sales termominerales, el sistema entra en tensión, pues la alta salinidad amenaza la biodiversidad y se convierte en fuente de conflictos por el uso del agua en la cuenca. Este trabajo recopiló datos de conductividad, precipitación de treinta años y batimetría, procesados, analizados y modelados, para presentar la variabilidad temporal (periodos contrastantes secos y húmedos) y espacial. De igual forma se realizaron ensayos de ecotoxicidad para evidenciar los posibles efectos de la salinización sobre el ecosistema, la biota y los riesgos asociados con cambios en la hidroclimatología de la zona. Los resultados señalan que el lago es altamente sensible a las disminuciones de precipitaciones que favorecen la acumulación de las sales hidrotermales provenientes de su cuenca y afloramientos, lo que acentúa la eutrofización cultural, lo que puede conducir a fenómenos que afecten el ecosistema y el potencial agropecuario de la zona de influencia.
\end{abstract}

Palabras clave: ecotoxicología; hidroclimatología; impacto ecológico; lago Sochagota; sales termominerales.

Recibido: 30/07/2020 Aceptado: 29/12/2020 Disponible en línea: 23/07/2021

Cómo citar: J. C. Monroy Ramírez, A. J. Espinosa Ramírez, y W. A. Jiménez Avella, «Hidroclimatología local e impactos en el lago Sochagota, Paipa, Boyacá», Cien.Ing.Neogranadina, vol. 31, n. 1, pp. 53 72, jul. 2021.

* Artículo de investigación.

a Ingeniero ambiental, Universidad Pedagógica y Tecnología de Colombia, Tunja, Colombia. Correo electrónico: juan.monroy01@uptc.edu.co ORCID: https://orcid.org/0000-0002-9843-889X

b Doctora en Salud Pública, Universidad Nacional de Colombia. Magíster en Ciencias, bióloga. Universidad Pedagógica y Tecnológica de Colombia. Tunja, Colombia. Correo electrónico: adriana.espinosa@uptc.edu. co ORCID: https://orcid.org/0000-0001-8320-5674

c Magíster en Ingeniería, Universidad Nacional de Colombia. Docente, Universidad Pedagógica y Tecnológica de Colombia. Tunja, Colombia. Correo electrónico: wilson.jimenez01@uptc.edu.co. ORCID: https://orcid. org/0000-0002-0207-3452 


\section{Local Hydro-Climatology and Impacts on Sochagota Lake, Paipa, Boyacá}

Abstract: Lake Sochagota is a built system that acts as an oxidation pond. Its level is regulated. It has an outcrop of thermo-mineral water, and receives runoffs from acid sulphated soils and a portion of fresh water from the Chicamocha river. It discharges in the irrigation district of Usochicamocha. By increasing the concentration of thermo-mineral salts, the system comes into tension, as high salinity threatens biodiversity and becomes a source of conflict over water use in the basin. This paper shows conductivity, thirty-year precipitation and bathymetry data, processed, analyzed and modeled, to present temporal (dry and wet contrasting periods) and spatial variability. Similarly, ecotoxicity tests were conducted to demonstrate the possible effects of salinization on the ecosystem, biota and risks associated with changes in hydro-climatology in the area. The results indicate that the lake is highly sensitive to decreases in precipitation that favor the accumulation of hydrothermal salts from its basin and outcrops, which accentuates cultural eutrophication, this can lead to phenomena that affect the ecosystem and the agricultural potential of the zone of influence.

Keywords: Ecotoxicology, hydro-climatology, ecological impact, Lake Sochagota, thermo-mineral salts. 


\section{Introducción}

El lago Sochagota es un sistema somero, con bajo nivel de mezcla, lo cual propicia acumulación de sedimentos, aumento en la temperatura del agua por la radiación solar, mayor actividad biológica y, en la noche, estados de anoxia; además es un sistema regulado por una compuerta. El lago es alimentado por la quebrada Honda-río Salitre, que transporta una buena cantidad de sales, suministradas por las fuentes termales que aparecen en el área media y baja de la microcuenca del lago y son vertidas sin ningún tratamiento en el río Chicamocha [1].

Es un área protegida con denominación legal de "Distrito Regional de Manejo Integrado (DRMI) Lago Sochagota y la cuenca que lo alimenta", con un área conformada por 8139,11 hectáreas. El área es potencialmente estratégica para la conservación de la biodiversidad y de especial importancia dentro de los ecosistemas del departamento, por su elevada recarga y oferta hídrica que beneficia las comunidades que habitan zonas aledañas [2]. Paipa depende del turismo, centrado en piscinas que utilizan los afloramientos termales y el lago como fuente de ingresos. Asimismo, es un reconocido productor agropecuario con necesidades específicas de agua para riego. Los nacimientos de aguas termominerales se encuentran sobre la falla geológica de Boyacá, perteneciente al grupo de las alcalinas, sulfatadas, cloruradas y bicarbonatada, con alto contenido de sales de sulfato de sodio y calcio, y con menor concentración de carbonato de magnesio, cloruro de litio y alguna emanación radioactiva y considerada de alta temperatura [3].

Con esta dinámica territorial, el análisis se propuso (1) conocer el comportamiento de las sales disueltas en el agua del lago por la influencia termal, (2) evaluar su relación en tiempos hidrológicos contrastantes en un período de treinta años y (3) dilucidar los posibles impactos sobre las comunidades acuáticas. Esto tiene sentido, debido a que la problemática a largo plazo podría afectar las propiedades fisicoquímicas del agua y comprometer, además, el suelo en el Distrito de Riego del Alto Chicamocha (DRACH).

La salinidad está relacionada con fenómenos ambientales como la aridez climática, reflejada por una baja pluviometría, en combinación con una elevada evapotranspiración, debida a una condición climatológica seca, la composición del suelo y, en este caso en particular, por surgencias hidrotermales. A ello se suman los impactos al ecosistema por una alta salinidad, que comprometen el uso del agua para el desarrollo de actividades humanas. Las aguas cargadas con las características salinas presentadas durante esta investigación, si son descargadas al río Chicamocha y usadas para riego, pueden traer problemas en las raíces de los cultivos por sobrepasar el límite de tolerancia de sales, medido en la concentración de la conductividad eléctrica $(\mu \mathrm{S} / \mathrm{cm})$ e intoxicar el suelo [4].

De acuerdo con lo mencionado, se consideró necesario recopilar los datos de conductividad eléctrica en el lago Sochagota, por medio de registros históricos y toma de muestras in situ, en seis zonas de interés del lago. Estos datos indican la cantidad de sales que llegan al cuerpo de agua. Asimismo, se realizó el modelo espaciotemporal con los datos recopilados de conductividad, caudal, necesarios para las simulaciones de la variación de la conductividad, para condiciones hidroclimatológicas específicas (bajas y altas precipitaciones). Junto con lo anterior, se realizó el análisis de riesgo ecotoxicológico por las sales, a través de ensayos de toxicología acuática en laboratorio.

Las mediciones en el agua permiten clasificarlas en función de su salinidad [5]:

Dulces: menos de $0,5 \mathrm{~g} / 1$

Oligohalinas: $0,5-4 \mathrm{~g} / \mathrm{l}$

Mesohalinas: 4-18 g/l

Polihalinas: $18-30 \mathrm{~g} / \mathrm{l}$

Euhalinas: $30-40 \mathrm{~g} / 1$

Hipersalinas: más de $40 \mathrm{~g} / \mathrm{l}$

En muchos ecosistemas, el exceso de salinidad limita la supervivencia de organismos de agua dulce. Ello genera efectos negativos, debido a que la salinidad es una condición ambiental que influye en su abundancia y desarrollo, toda vez que somete al organismo a un estrés osmótico, si este no se adapta a las concentraciones salinas [6]. En cuanto a la hidroclimatología local, la cuenca del río 
Salitre en su estación agrometeorológica Tunguavita informa de $881 \mathrm{~mm}$ de lluvia total promedio.

Durante el año, las lluvias se distribuyen en dos temporadas secas y dos temporadas lluviosas - carácter bimodal- [7]. Fenómenos macroclimáticos como El Niño o La Niña y la Oscilación del Sur (Enso), afectan la hidroclimatología de los Andes tropicales, lo cual modifica las condiciones normales regionales [8], como la precipitación y, en este caso, la conductividad eléctrica, la cual depende de la cantidad de agua no salina que entra al lago y está influenciada por la precipitación.

El software Iber es un modelo matemático que usa ecuaciones de aguas someras o poco profundas conocidas como $2 D$ shallow water equations o simplemente ecuaciones de Saint Venant. Las resuelve intentando conocer los valores que toman las variables hidráulicas como el calado (profundidad), caudales, velocidad y otros. Para ello, se vale de métodos numéricos de determinadas ecuaciones asignadas según el caso requiera [9]. El modelo de salinidad en Iber 2.5 resuelve la ecuación de transporte de sales, promediando la profundidad y el régimen no permanente, utilizando datos de caudal y temperatura del agua, variables de las cuales depende la salinidad.
Con la necesidad creciente en los países en desarrollo, como el nuestro, de contar con procedimientos de bajo costo y corta duración en la evaluación ambiental, el ensayo de toxicidad aguda permite verificar, en un periodo corto, el estrés ambiental sobre el ecosistema. Para evaluar la ecotoxicidad ambiental, se utiliza la experimentación con diferentes organismos acuáticos, generalmente representantes importantes de las redes tróficas. El amplio rango de sensibilidades de los diferentes organismos hace recomendable utilizar ciertas especies en las evaluaciones de ecotoxicidad. Para este caso, se remarca la importancia de los ensayos ecotoxicológicos con Hydra viridissima y Lactuca sativa L., [10]-[12] para la evaluación de cuerpos lénticos, como el lago Sochagota.

\section{Materiales y métodos}

Para los análisis, se incluyeron variables como las condiciones hidrológicas, datos de conductividad de 30 años (1987-2019) y los más actuales, durante cinco fases campo, desarrolladas por los autores, para poder hacer las modelaciones subsiguientes. Asimismo, en la fase experimental se obtuvieron respuestas de los ensayos de ecotoxicidad y los análisis fisicoquímicos del agua. La metodología general se describe en la figura 1 .

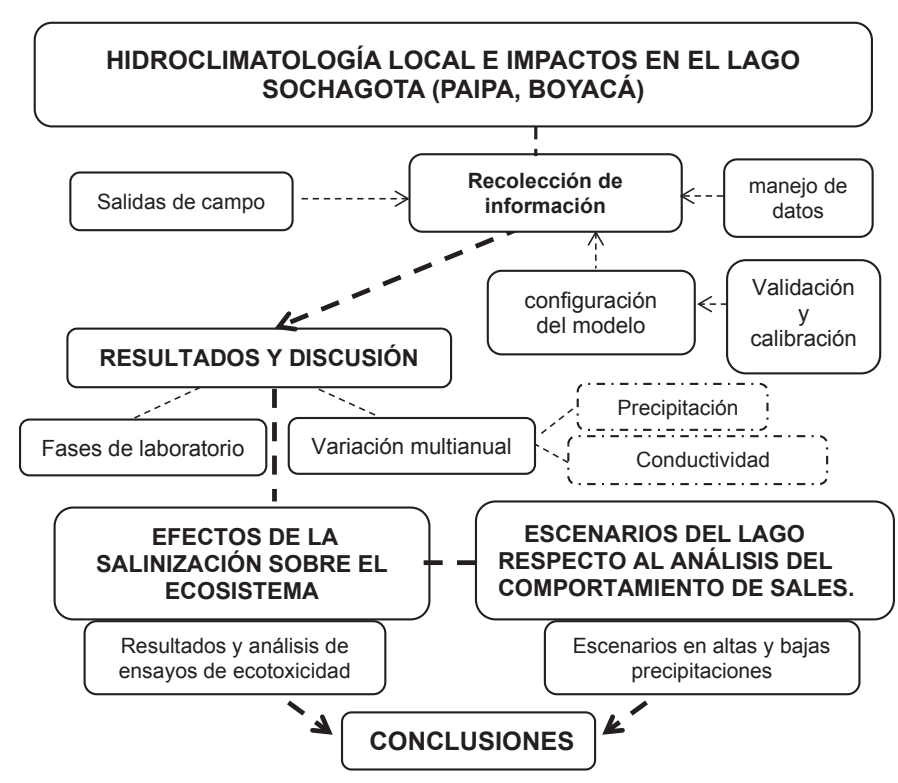

Figura 1. Metodología general del estudio.

Fuente: elaboración propia. 


\section{Fuentes de información}

Se consultaron las bibliotecas de Corpoboyacá, Red Vital sa y bibliotecas universitarias. Además, artículos relacionados con la temática de este trabajo en bases de datos. De ese modo, se encontraron estudios previos e información en torno al lago Sochagota.

\section{Área de estudio}

El lago de Sochagota es un sistema acuático construido en 1956 por el Estado colombiano, para explotar el potencial turístico de Paipa. Está ubicado entre las coordenadas planas $\mathrm{X}=1^{\prime} 127,800$,

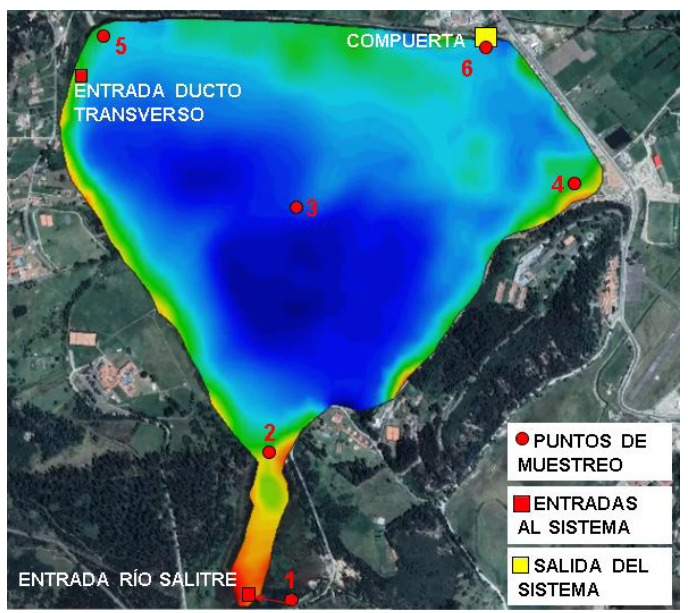

$-1^{\prime} 129.800 \mathrm{~N}$ y $\mathrm{Y}=\mathrm{l}^{\prime} 105,250,-\mathrm{l}^{\prime} 107,000 \mathrm{E}$, en la cuenca alta del río Chicamocha, ubicado en la parte norte de la microcuenca del río Salitre, al sur de Paipa (Boyacá), nororiente de Colombia, a los $2496 \mathrm{msnm}$. Posee un espejo de agua de $163 \mathrm{ha}$, un volumen de 4557000 metros cúbicos, una profundidad media de 2,8 metros, y máxima de 3,20 metros (batimetría Plan de Manejo ambiental 2009), represa en su primer metro de profundidad, aproximadamente 1623000 metros cúbicos, lo cual significa que por cada centímetro que baje el nivel, el lago pierde 16230 metros cúbicos de agua [11].

Puntos de muestreo:

1. Entrada sistema quebrada Honda-río Salitre

2. Entrada del río Salitre a unos $200 \mathrm{~m}$ adelante

3. Centro del lago

4. Muelle de los Jarillones

5. Muelle de la Fragata

6. Compuerta salida lago

Figura 2. En colores batimetría. Ubicación puntos de muestreo, entradas y salida del sistema. Fuente: elaboración propia.

\section{Metodología}

\section{Salidas de campo}

Se realizaron cinco visitas en periodos hidroclimatológicos contrastantes (secos y húmedos), entre los meses de marzo y octubre de 2019. Se tomaron datos in situ y muestras de agua en seis puntos dentro del lago, en los afluentes principales centro y salida por la compuerta (tabla 1).

Tabla 1. Condiciones hidroclimatológicas y puntos de muestreo

\begin{tabular}{llllll}
\hline Muestreo 1 & Muestreo 2 & Muestreo 3 & Muestreo 4 & Muestreo 5 \\
Seco & Húmedo & Seco & Húmedo & Húmedo \\
(menores precipitaciones) & (mayores & (menores & (mayores & (mayores precipitaciones) \\
$10 / 03 / 2019$ & precipitaciones) & precipitaciones) & precipitaciones) & 20/10/2019 \\
& $9 / 06 / 2019$ & $4 / 08 / 2019$ & $1 / 09 / 2019$ & \\
\hline
\end{tabular}




\begin{tabular}{|c|c|c|c|c|c|}
\hline p1 & p2 & p3 & p4 & p5 & p6 \\
\hline Entrada del río Salitre & $\begin{array}{l}200 \text { m delante de } \\
\text { entrada del río Salitre }\end{array}$ & Centro del lago & $\begin{array}{l}\text { Muelle de los } \\
\text { Jarillones }\end{array}$ & $\begin{array}{l}\text { Muelle de la } \\
\text { Fragata }\end{array}$ & Compuerta salida \\
\hline$x=5,7529059$ & $x=5,7547539$ & $x=5,7631755$ & $x=5,76273$ & $x=5,76764$ & $x=5,731155$ \\
\hline$y=-73,118541$ & $y=-73,120781$ & $y=-73,111988$ & $y=-73,115$ & $y=-73,12592$ & $y=-73,12592$ \\
\hline
\end{tabular}

Fuente: elaboración propia.

En cada punto de muestreo, se realizaron mediciones in situ de caudal [12], pH, conductividad, oxígeno disuelto (método volumétrico según Winkler con Kit MQuant Merck [13]) y temperatura. También se recolectó un litro de agua para las mediciones de turbiedad, realizadas luego en el laboratorio de Ingeniería ambiental de la UPTC [14], y los ensayos de ecotoxicidad en el laboratorio Ecotox-Udesa.

\section{Ensayos de ecotoxicidad acuática aguda}

Para la evaluación del lago Sochagota, se procesaron $\mathrm{n}=30$ muestras, mediante los ensayos de toxicidad aguda con Hydra viridissima, a 96 horas e inhibición del crecimiento en Lactuca sativa, a 120 horas, con las muestras recolectadas de los diferentes puntos de interés. Con los cuales se determinó el efecto negativo sobre la germinación, la inhibición del crecimiento en tallo y raíz y la letalidad y subletalidad con $H$. viridissima, que es un biomodelo de alta sensibilidad, como representante de los organismos animales, según los protocolos de ensayo [10]-[12].

\section{Manejo de datos}

Se organizó una base de datos en Excel, con los registros obtenidos de Corpoboyacá, el Ideam y artículos de investigación. Se ordenaron y homogeneizaron a unidades de conductividad eléctrica $(\mu \mathrm{S} / \mathrm{cm})$ y por meses, se calcularon los valores promedios y graficaron con diagramas de puntos.

\section{Caracterización de condiciones hidrodinámicas y de contorno del lago}

Este cuerpo de agua es léntico de flujo cerrado; tiene una salida asociada a una estructura hidráulica del tipo compuerta. Una vez se conoce el caudal de entrada, deben tenerse en cuenta también las condiciones de rugosidad para el lago, predeterminadas por el uso del suelo de la superficie, la condición de contorno y de entrada para salinidad, el calado o profundidad del cuerpo de agua, la condición inicial del medio y se cuenta con el aporte de precipitación en diferentes momentos.

\section{Configuración del modelo}

Después de la recolección de datos teóricos y experimentales en cuanto a conductividad eléctrica, se inició la construcción de los datos geográficos requeridos como entrada Iber. A partir de las curvas de nivel, se realizó la conversión de Ascir a un formato Raster por medio de ArcToolbox/Conversión Tools/To Raster/Ascir. De esta manera, pudo usarse la información en el software Iber. Se hizo una conversión de unidades de las variables de estudio, para transformarlas a las unidades de Iber, necesarias para cada simulación.

En Iber, se introducen los datos hidrodinámicos, de calidad de agua y datos del problema; se selecciona la herramienta Calcular, y se realiza la simulación para el periodo de tiempo objeto de estudio y para la frecuencia de análisis de los datos (en este caso, 24 horas cada 10 minutos; y 30 días, cada media hora). Este procedimiento se recreó cuatro veces, ya que se deseaba analizar la variación de la salinidad en diferentes escenarios, uno diario y uno mensual para cada condición, en este caso, durante épocas de menores y mayores precipitaciones (condiciones seca y húmeda). Los modelos desarrollados y sus resultados son clasificados por condición de la siguiente manera: un escenario diario y un escenario mensual durante época de 
menores precipitaciones (condición seca) y un escenario diario y mensual durante época de mayores precipitaciones (condición húmeda).

El modelo de salinidad, que resuelve la ecuación que modela el transporte de sal promediada en profundidad en régimen no permanente, utiliza el campo de velocidades y turbulencia proporcionado por los módulos correspondientes. Como las sales son sustancias conservativas, la ecuación de transporte correspondiente a la salinidad no incluye términos fuente, como se describe en el manual de referencia del módulo de calidad de aguas de Iber [1], [9].

\section{Condiciones hidrodinámicas iniciales}

Se asignó la cota de agua para la simulación, además de la condición inicial de la salinidad y temperatura del lago; se asignó al coeficiente de difusión de las sales un valor de $1,1 \times 10^{-9} \mathrm{~m}^{2} / \mathrm{s}$ [15], para las simulaciones. Se detalló que existe otra entrada aportante de caudal al lago, un ducto trasverso proveniente de los lagos de enfriamiento de la termoeléctrica que aporta agua del río Chicamocha, para mejorar las condiciones del lago por su déficit hídrico [16]. La única salida es el canal de la compuerta que libera sus aguas al río Chicamocha cuando se hace esta operación (tabla 2).

Tabla 2. Afluentes del lago Sochagota

\begin{tabular}{lcccc} 
Fuente & Caudal medio $\left(\mathbf{m}^{3} / \mathbf{s}\right)$ & Oferta anual de caudal ecológico $\left(\mathbf{m}^{\mathbf{3}} / \mathbf{s}\right)$ & Caudal ecológico $\left(\mathbf{m}^{3} / \mathbf{s}\right)$ \\
\hline Río Salitre & 1,6 & 11984949 & 0,34 \\
\hline Ducto transverso & $0,047^{\circ}$ & 1483176 & $0,047^{\circ}$ \\
\hline
\end{tabular}

Fuente: elaboración propia a partir de datos de Corpoboyacá [17] y Red Vital [18].

\section{Validación y calibración de modelos}

La calibración para cada escenario fue evaluada en Iber 2.5, primero, haciendo una simulación de 24 horas por cada condición, una para menores precipitaciones y una para mayores precipitaciones. Se evaluó por 24 horas, cada 10 minutos, donde se compararon los datos de conductividad eléctrica, reportados por el modelo, con los registros de conductividad eléctrica de la estación de calidad de agua (reporta datos cada hora), instalada en la compuerta del lago por Corpoboyacá (salida del sistema, punto 6 de monitoreo del estudio y zona de mezcla del sistema).

De esta manera, tanto para la condición de menores precipitaciones como la de mayores precipitaciones, el escenario diario reportó una diferencia de $7 \%$ entre los datos reportados por la simulación a 24 horas, con respecto a los de la estación de calidad de agua. Ello demostró la validez de los modelos diarios plateados y permitió continuar con un escenario mensual para cada condición. Con los mismos escenarios diarios, ya validados, se analizó la salinidad cada media hora durante 30 días, para las condiciones de menores y mayores precipitaciones, con los promedios de los datos recopilados.

\section{Resultados y discusión}

\section{Variación multianual precipitación}

Se recopilaron registros desde enero de 1987 hasta febrero de 2019 ( $n=390)$. Se evidenciaron dos temporadas secas y dos temporadas lluviosas (carácter bimodal) en el año. 


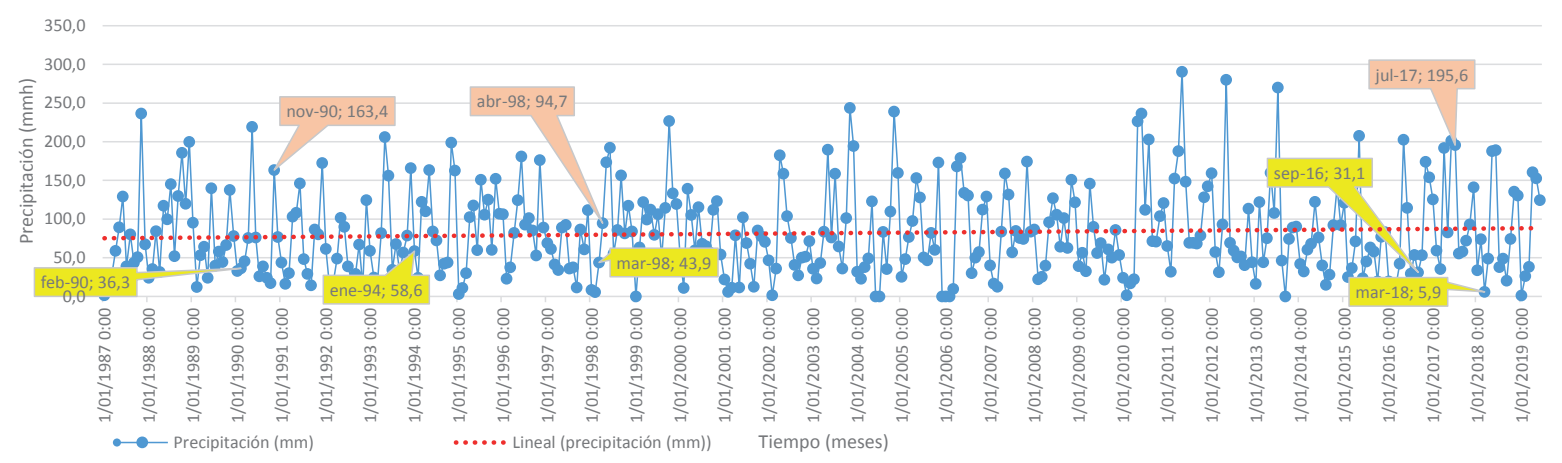

Figura 3. Precipitación total mensual 1987-2019 ( $n=390)$.

Fuente: elaboración propia con datos de la estación Agrometereológica Tunguavita del Ideam [7].

Los meses predominantemente secos son diciembre, enero, febrero, julio y agosto; mientras que las temporadas de lluvia se extienden desde finales de marzo hasta principios de junio, y desde septiembre hasta comienzos de noviembre. En los meses secos de principios de año, llueve de 4 a 6 días/mes; en los intermedios, en promedio 17 días lluvia/mes y en los meses de mayores lluvias puede llover entre 18 y 20 días/mes [1], [7].

Con el régimen de lluvias estimado sobre la cuenca aportante al lago, primero, se establecieron relaciones entre la $\mathrm{CE}$ y las condiciones hidroclimáticas locales, segundo, se recopiló la variación de precipitación mensual y la CE, desde 1987 hasta junio del 2019.

La figura 3 muestra el comportamiento multianual de las precipitaciones sobre la cuenca que alimenta el lago Sochagota. Las mayores precipitaciones ocurren en abril, mayo y noviembre, equivalente a la de los meses con mayores aportes de caudal al lago desde su microcuenca. El periodo seco fue en enero-abril. Se registran anualmente en forma reiterada los valores más críticos de precipitación y, por tanto, de menor entrada de caudal al lago durante los últimos 30 años, lo que favoreció el aumento en la concentración de sales para este periodo.

\section{Variación multianual de la conductividad eléctrica}

Se registraron menores reportes de conductividad eléctrica (CE) para los meses que predomina una condición húmeda y de mayor precipitación (julio, abril y noviembre) con registros que oscilan en el rango 1500-4000 $\mu \mathrm{S} / \mathrm{cm}$. Para los meses de condición seca (enero, febrero y marzo), se presentaron los registros más altos, oscilantes en el intervalo 4000-8000 $\mu \mathrm{S} / \mathrm{m}$, regularmente (figura 4), debido a entradas de aguas termominerales, cargadas con sales, de su cuenca principal, y por afloramientos en su interior. Además, durante el periodo seco, existe la influencia de mayor evaporación y menor caudal de agua no salina entrante.

Sin embargo, antrópicamente, la calidad del agua del sistema varía dependiendo de la condición de operación de la compuerta, ocurrida solo cuando hay exceso de agua embalsada (época de mayores precipitaciones) o cuando se presentan malas condiciones sanitarias, como malos olores (generalmente durante época de menores precipitaciones). Ello hace que las aguas del sistema se renueven y se establezcan nuevas concentraciones para la $\mathrm{CE}$, generalmente disminuyendo en el lago tras la operación de apertura.

Fenómenos macroclimáticos como El Niño o La Niña y la Oscilación del Sur (Enso), que afectan la variabilidad hidroclimática de los Andes tropicales [1], [8], modifican las condiciones regionales típicas, como la precipitación y, en este caso, la conductividad eléctrica. Este parámetro, que depende de la cantidad de agua no salina que entra al lago, está influenciado por la precipitación. Así se normalizan para el lago valores cercanos y mayores a los $10000 \mu \mathrm{S} / \mathrm{cm}$ en épocas de El Niño por 
las bajas precipitaciones; y menores de $2000 \mu \mathrm{S} / \mathrm{cm}$ con presencia de La Niña, por el aumento de las lluvias.

Con la operación de la compuerta, se descargan aguas al río Chicamocha desde el lago y, de esta manera, se modifican los valores para la CE en el sistema. Durante 2016, se reportó mala calidad sanitaria en el lago y altos valores de CE. Ello evidencia estrés salino sobre los organismos del hidrosistema, por conductividades superiores a los $10000(\mu \mathrm{S} / \mathrm{m})$, como en septiembre de ese año, que trajo consigo alteraciones del hidrosistema y mortandad de peces como la carpa común -Cyprinus carpio- (figura 6), la cual no toleró las condiciones del medio en ese momento, a pesar de ser una especie caracterizada por su capacidad de vivir en aguas con poca disponibilidad de oxígeno y malas características [18].

A partir de 2016, se declaró una emergencia sanitaria, como signo de alerta de los problemas que presentaba el lago, y se tomaron medidas como la apertura de la compuerta y la activación del ducto trasverso, que aporta aguas del río Chicamocha. Esto evidenció síntomas de mejora de calidad del agua, con disminución de la CE en los datos posteriores a septiembre de 2016 (figura 4).

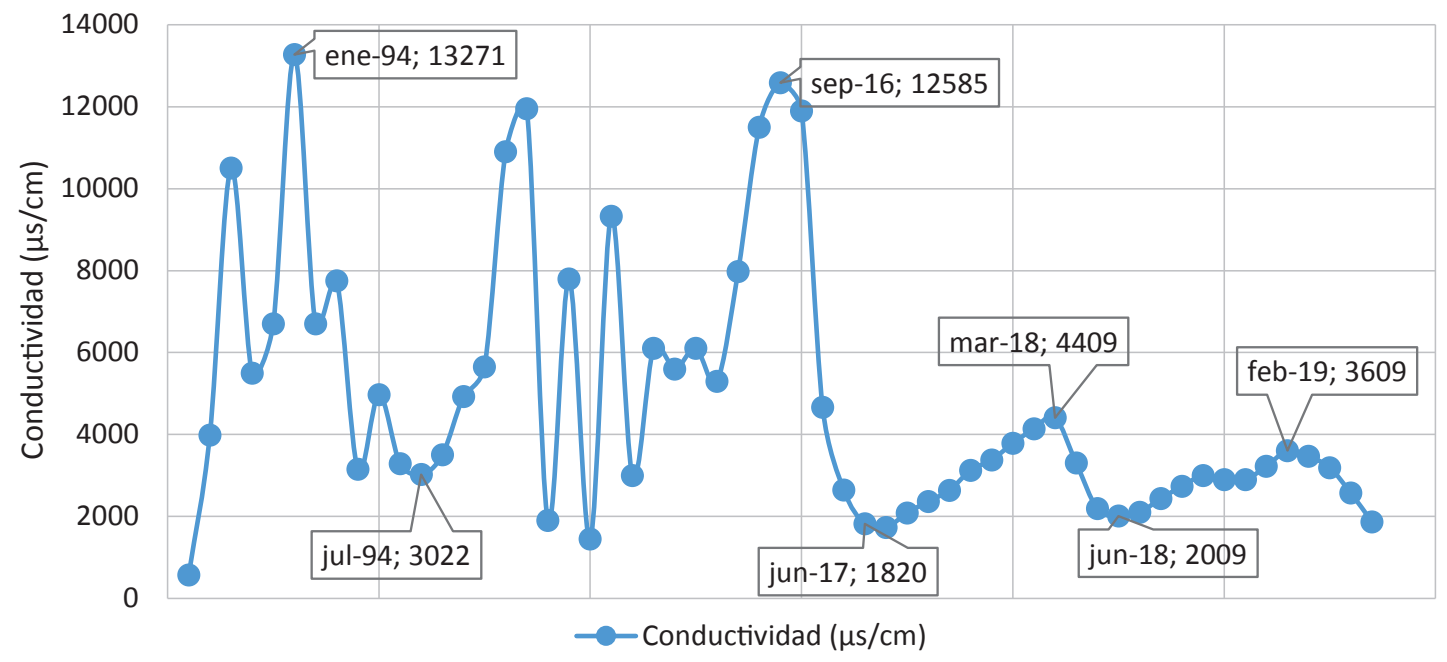

Figura 4. Conductividad eléctrica del lago de Sochagota (1986-2019).

Fuente: elaboración propia con registros del lago Sochagota de CE de Corpoboyacá [17].

Desde los primeros registros mensuales completos encontrados del lago Sochagota, se tiene el régimen de lluvias sobre la cuenca del río Salitre, mes a mes, y los valores de $\mathrm{CE}$, lo que indica la relación entre estas variables. Mayores precipitaciones implican menor CE y menores precipitaciones, mayor tensión en salinidad del lago (figura 5). Sin embargo, antes de 2016 no se contaba registros o reportes de calidad de agua frecuentes, por esto, se tomó como ejemplo el año 2018, pues pueden evaluarse los datos completos para el todo el año, desde la crisis y con las medidas correctivas implementadas. 


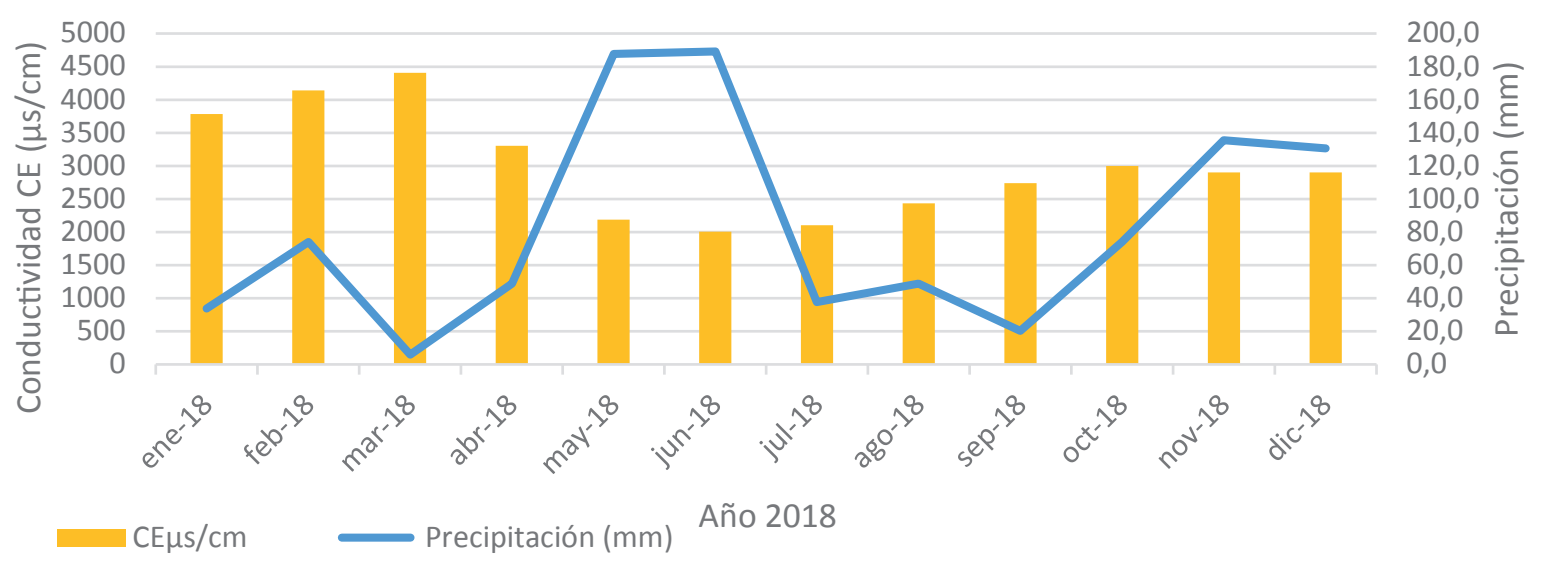

Figura 5. Conductividad eléctrica y precipitación (n=12), 2018.

Fuente: elaboración propia.

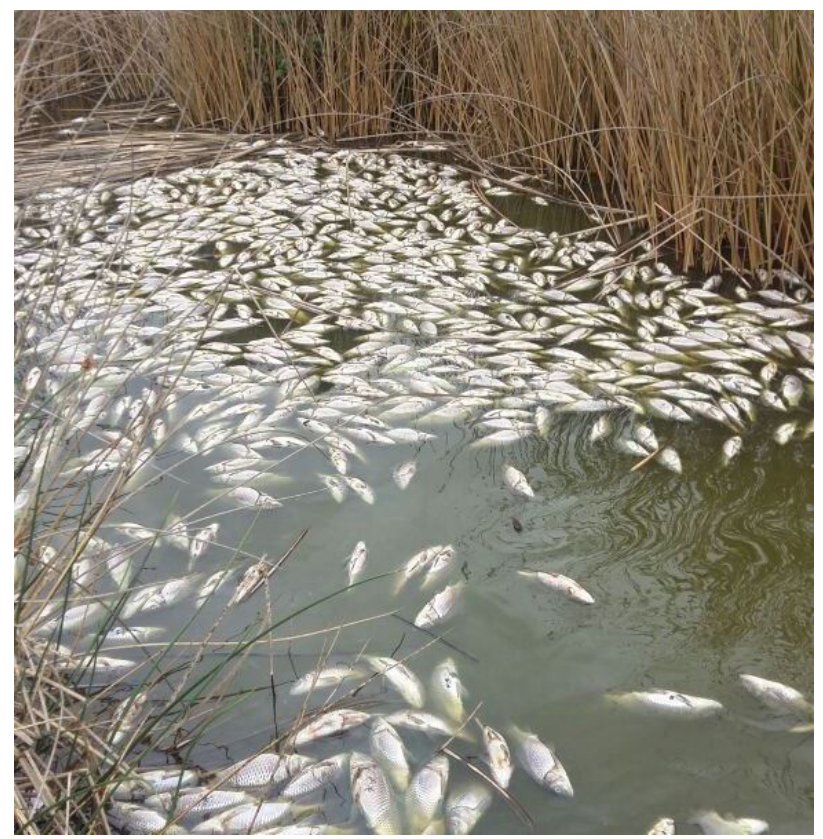

Figura 6. Mortandad de peces en el lago Sochagota, 2016.

Fuente: tomado de El Tiempo [19].

Valores más recientes reportados del lago (2018) señalan la efectividad de las medidas de mitigación, con reportes de CE inferiores a los $5000 \mu \mathrm{S} / \mathrm{cm}$, mantenidos desde 2017 (año en que se implementaron las medidas correctivas). Con el cambio de las dinámicas en el lago, tras las medidas correctivas adoptadas, como seguimiento a las variables fisicoquímicas del sistema, la habilitación del ducto que suministra aguas del río Chicamocha, y la regulación de las aguas a través de la apertura de la compuerta, se intentó restaurar la calidad ecológica del hidrosistema [20].

\section{Fase de laboratorio}

A partir de los datos recopilados en la fase de campo, se obtuvieron los valores de conductividad 
eléctrica (tabla 3), que señalan al punto 1 (entrada al lago) como aquel de mayores registros de conductividad eléctrica en el sistema, el punto 6 (compuerta) como zona de mezcla del lago, antes de descargar las aguas al río Chicamocha.
Adicionalmente, las temperaturas medidas del agua también fueron altas, lo que indica presión adicional a la biota, por la disminución de la concentración de oxígeno probablemente asociada con la baja profundidad del sistema.

Tabla 3. Variables in situ en cada punto de muestreo para calibrar modelo y escenarios

\begin{tabular}{|c|c|c|c|c|c|c|c|c|}
\hline & \multirow[t]{2}{*}{ Variable } & \multicolumn{5}{|c|}{ Muestreos } & \multirow{2}{*}{$\begin{array}{l}\text { Promedio } \\
(n=5)\end{array}$} & \multirow[b]{2}{*}{ Unidad Ibe } \\
\hline & & $\frac{1}{10 / 03 / 2019}$ & $\begin{array}{c}2 \\
9 / 06 / 2019\end{array}$ & $\begin{array}{c}3 \\
4 / 08 / 2019\end{array}$ & $\begin{array}{c}4 \\
1 / 09 / 2019\end{array}$ & $\begin{array}{c}5 \\
20 / 10 / 2019\end{array}$ & & \\
\hline \multirow[t]{2}{*}{ Punto 1} & $\mathrm{CE}$ & 3469 & 1626 & 2620 & 7810 & 7250 & 4018,17 & $\mathrm{Kg} / \mathrm{m}^{3}$ \\
\hline & Temperatura & 16 & 16 & 18 & 18 & 17 & 17,3 & ${ }^{\circ} \mathrm{C}$ \\
\hline \multirow[t]{2}{*}{ Punto 2} & CE & 3660 & 1593 & 2730 & 2980 & 3730 & 2740,75 & $\mathrm{Kg} / \mathrm{m}^{3}$ \\
\hline & Temperatura & 19 & 16 & 17 & 17 & 17 & 17,3 & ${ }^{\circ} \mathrm{C}$ \\
\hline \multirow[t]{2}{*}{ Punto 3} & CE & 3530 & 2110 & 2660 & 2980 & 3320 & 2820 & $\mathrm{Kg} / \mathrm{m}^{3}$ \\
\hline & Temperatura & 19 & 16 & 18 & 18 & 17 & 17,8 & ${ }^{\circ} \mathrm{C}$ \\
\hline \multirow[t]{2}{*}{ Punto 4} & CE & 3680 & 2220 & 2620 & 2980 & 3070 & 2875 & $\mathrm{Kg} / \mathrm{m}^{3}$ \\
\hline & Temperatura & 21 & 16 & 18 & 18 & 18 & 18,3 & ${ }^{\circ} \mathrm{C}$ \\
\hline \multirow[t]{2}{*}{ Punto 5} & CE & 3300 & 2300 & 2740 & 3000 & 3260 & 2835 & $\mathrm{Kg} / \mathrm{m}^{3}$ \\
\hline & Temperatura & 21 & 15 & 18 & 18 & 18 & 18,0 & ${ }^{\circ} \mathrm{C}$ \\
\hline \multirow[t]{2}{*}{ Punto 6} & CE & 3570 & 2220 & 2670 & 2980 & 3280 & 2860 & $\mathrm{Kg} / \mathrm{m}^{3}$ \\
\hline & Temperatura & 22 & 15 & 18 & 18 & 18 & 18,3 & ${ }^{\circ} \mathrm{C}$ \\
\hline
\end{tabular}

Conductividad eléctrica (CE) en micro-Siemens por centímetro $(\mu \mathrm{S} / \mathrm{cm})$; temperatura en grados centígrados $\left({ }^{\circ} \mathrm{C}\right)$.

Fuente: elaboración propia.

\section{Efectos de la salinización - ensayos de ecotoxicidad}

Con la necesidad creciente de los países en desarrollo de contar con procedimientos de evaluación ambiental, sencillos, de bajo costo y corta duración, los ensayos de toxicidad aguda permitieron verificar, en un plazo corto, el estrés ambiental sobre el ecosistema. Los vertimientos al ambiente pueden causar efectos muy variados, ya sea sobre un conjunto de organismos de una especie aislada (efectos tóxicos), o bien sobre los ecosistemas y el equilibrio ambiental general (efectos ecotóxicos); los cuales pueden ser inmediatos o de largo plazo [21].

\section{Germinación e inhibición crecimiento en lechuga (Lactuca sativa)}

Un objetivo importante de las pruebas de toxicidad es, por un lado, valorar el posible impacto sobre los ecosistemas naturales y, por otro, alertar de manera temprana sobre los potenciales perjuicios por contaminación del agua. El ensayo de L. sativa evaluó efectos sobre la germinación (efecto letal) y sobre la inhibición de la elongación de la raíz y tallo, considerados efectos subletales [10], [11].

$\mathrm{Al}$ evaluar las muestras del lago sobre la germinación de semillas, en los diferentes muestreos la inhibición no sobrepasó el $25 \%$ : se encontró entre 
5 y $21 \%$ en los puntos evaluados (figura 7). Ello indica que el agua podría inhibir ligeramente la germinación de semillas que pueden sembrarse en las áreas que la utilizan como riego, fenómeno a contrastarse con las comunidades de agricultores de la zona.
El muestreo 2 reveló menor inhibición en todo el estudio, tanto en la germinación como en el crecimiento del tallo. Además, fue el mes que mayor pluviosidad presentó durante los muestreos. La inhibición de la elongación del tallo, para las diferentes muestras del lago tomadas en las campañas de muestreo se presenta en la figura 8.

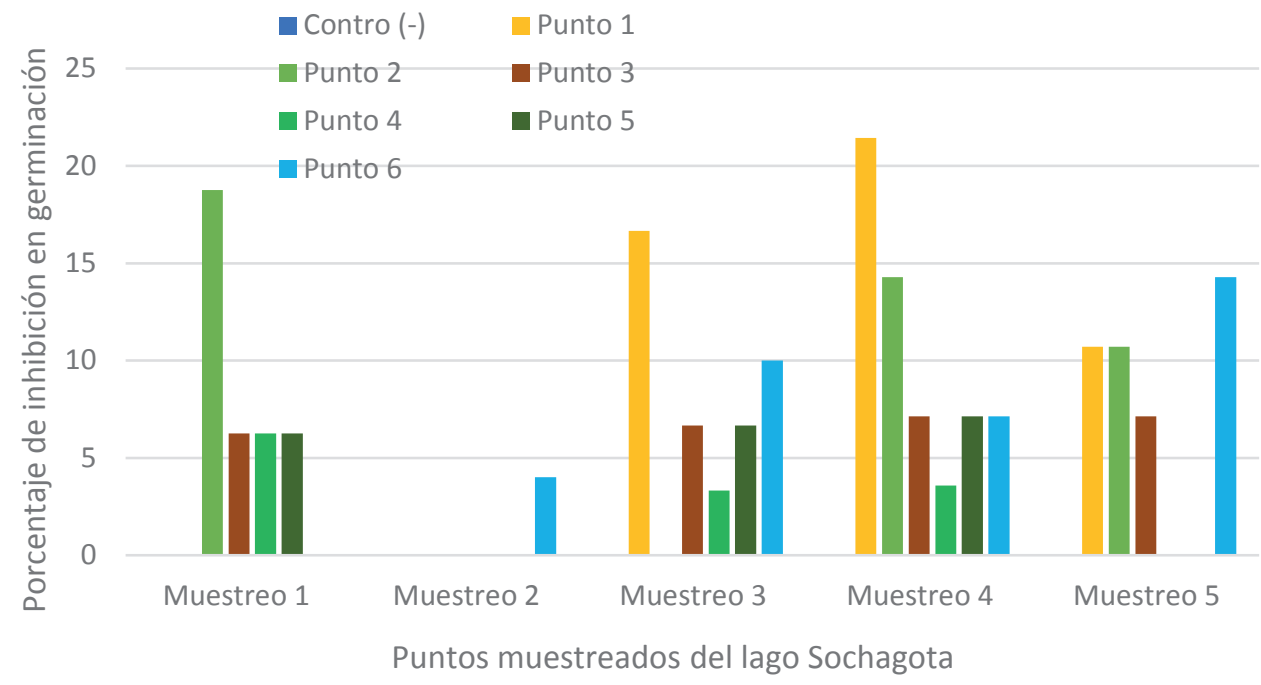

Figura 7. Inhibición de germinación en semillas de L. sativa con muestras de agua ( $\mathrm{n}=30)$. Fuente: elaboración propia.

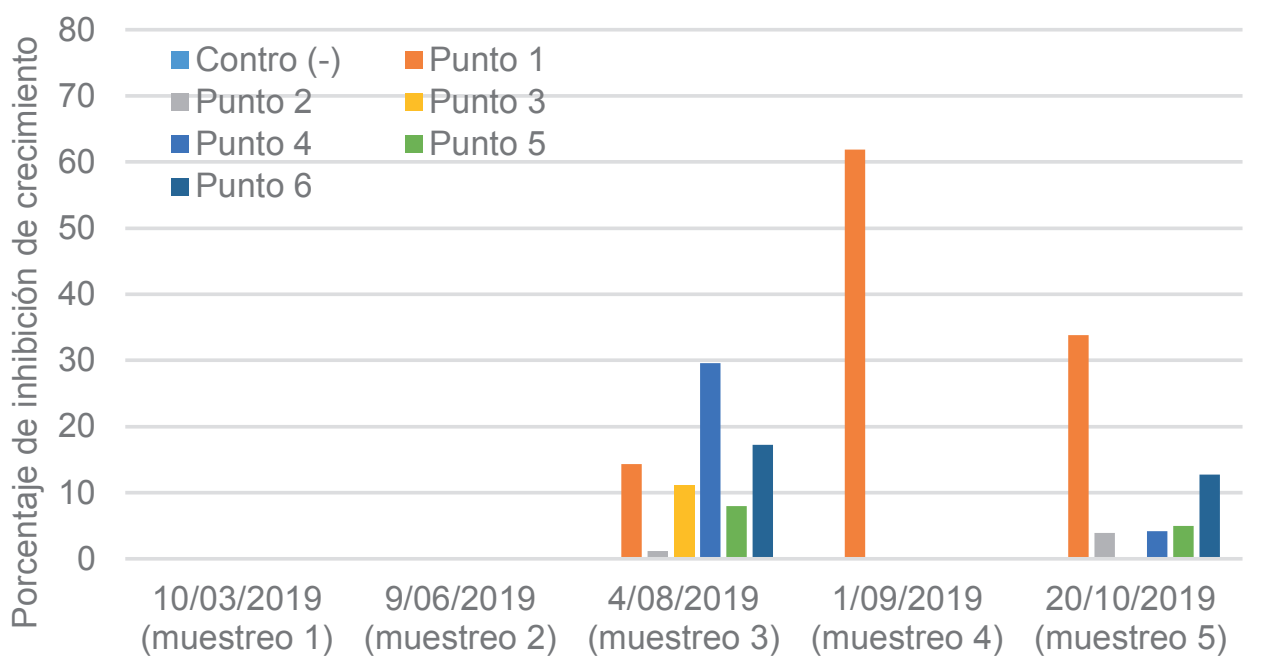

Figura 8. Inhibición crecimiento del tallo de L. sativa con muestras de agua $(n=30)$.

Fuente: elaboración propia. 
Para los muestreos 1 y 2 , el crecimiento del tallo fue superior a la elongación de los individuos del control negativo, debido a los nutrientes presentes en el agua. Esto puede influenciar el metabolismo de la planta y estimular su crecimiento. Estos resultados son similares a los encontrados para el muestreo 4, en todos los puntos, excepto en el de ingreso de la quebrada Honda-río Salitre, donde se obtuvo la mayor inhibición de crecimiento (>60\%) seguida de los muestreos 3 (33\%) y 5 (14\%).
El coeficiente de variación (Cv) para los datos de la elongación de tallo estuvo en el rango 20-55\% en su mayoría, con algunas excepciones. Ello determina que hay una alta varianza de estos e indica que la respuesta para tallo generó la principal afectación asociada en el punto Honda-río Salitre, probablemente debida a que, durante el cuarto muestreo, se presentaron niveles muy superiores de conductividad en ese punto.

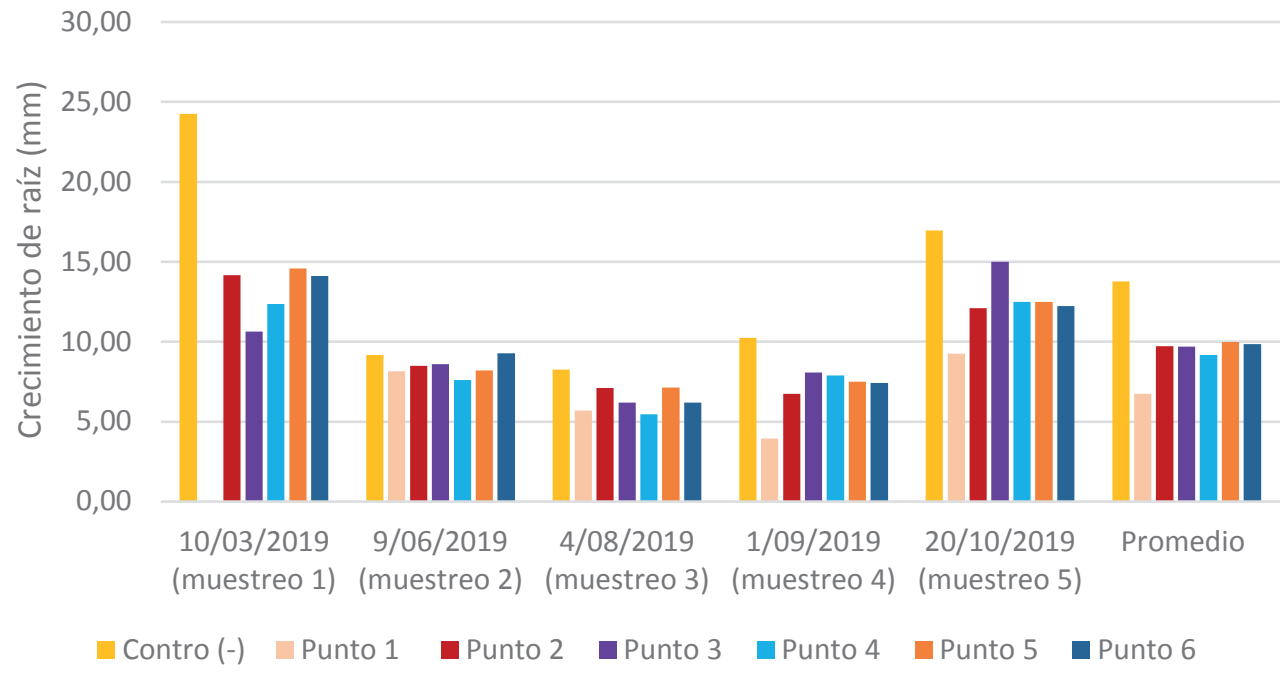

Figura 9. Inhibición del crecimiento de la raíz de L. sativa, con muestras del lago (n=30).

Fuente: elaboración propia.

Se determinó que la raíz fue el órgano más sensible frente a las aguas del lago (figura 9), ya que en veintiocho de las muestras se comprobó inhibición de su crecimiento, con diferencias de 6-61\%. Se resalta que, en el muestreo 1 , se presentaron inhibiciones mayores a $40 \%$ en todos los casos; contrastado con el muestreo 2 con la menor inhibición por debajo del $20 \%$; ya que, durante esta fase, se reportaron los menores registros de CE del agua. Estos registros reflejan la influencia ecotóxica de las aguas del lago en organismos vegetales como el ensayado.

Con el sistema Quebrada Honda-río Salitre (punto 1) se presentó la mayor variabilidad con respecto al control negativo. Este hecho corroboró que las aguas inhiben el crecimiento de la raíz. Las muestras del lago (puntos 2-6) presentaron una reducción en su elongación. Para el caso de la raíz, es apreciable que, durante el segundo muestreo, se dieron los menores reportes de inhibición, asociados con los menores registros para las variables de calidad del agua, debido a la renovación de aguas en ese momento hidrológico.

\section{Efectos letales y subletales en Hydra viridissima}

En algunas investigaciones, ha incluido preferencialmente el uso de $H$. attenuata, como organismos modelo para evaluar toxicidad acuática. Sin embargo, lo novedoso de este trabajo fue la evaluación de una especie nativa (Hydra viridissima), que se propone como modelo animal para diagnosticar la ecotoxicidad, mediante el reconocimiento de 
efectos subletales (bulbo y corto) y letales (tulipán y desintegración). En la figura 10, se ejemplifican las modificaciones en la estructura de las hidras. Este ensayo se realizó con observación cada 24 horas, hasta completar 96 horas de exposición. Se aclara que las muestras se evaluaron sin diluir.

Se resaltó la alta sensibilidad de esta especie al agua del lago, en todos los puntos, en las primeras 24 horas, ya que mostraron efectos subletales en todos los muestreos. Estos efectos oscilaron por encima del $55 \%$ en las primeras horas de exposición, tras entrar en contacto con las muestras de agua; en ese momento, se apreciaron cambios morfológicos de los tentáculos de cada individuo, con aparición de bulbos, rigidez y recogimiento de los tentáculos. Con respecto a la letalidad a las 24 horas, solo el punto de ingreso del agua del sistema quebrada Honda-río Salitre mostró afectaciones en los muestreos 4 y 5 , donde se encontraron desintegrados los organismos para las diferentes réplicas.
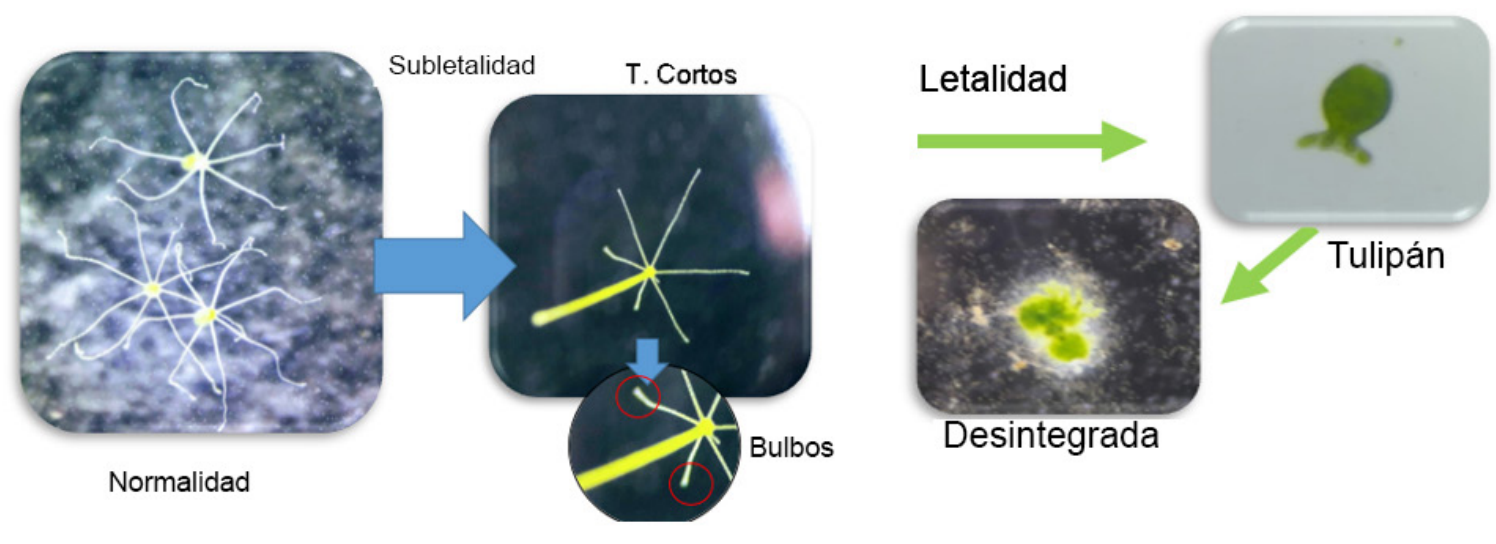

Figura 10. Cambio en morfología de estado de normalidad a estados de subletalidad (tentáculos cortos y bulbos), letalidad (tulipán y desintegrado) en $H$. viridissima.

Fuente: elaboración propia.

Los ensayos con Hydra viridissima se consideran los de mayor sensibilidad a las muestras, comparados con Lactuca sativa, organismo estándar de prueba en ensayos de fitotoxicidad. Se concluyó que las comunidades acuáticas del lago están sometidas a presiones permanentes, sin que se conozca si se están modificando aspectos de estructura y función de este sistema.

En el punto quebrada Honda-río Salitre, se transporta gran cantidad de sales, suministradas por las aguas termales que aparecen en la zona media e inferior de su subcuenca. Los efectos medidos se asociaron a presencia de aguas termominerales en el sector del municipio de Paipa, que afectan al suelo del Distrito de Riego del Alto Chicamocha -DRACH [22] y producen desagregación de partículas del suelo, causada por sulfatos de sodio, contaminación iónica por cloro y sodio, debido principalmente a un manejo inadecuado de las aguas sulfúricas [23].

De ese modo, las aguas cargadas con salinidad, presentadas durante esta investigación, deben considerarse objeto de estudio más especializado, ya que establecería, por un lado, si esta descarga al río Chicamocha puede modificar de manera importante características como la conductividad eléctrica; por otro, demostraría si estas aguas, al ser usadas para riego, pueden traer problemas a las raíces de los cultivos, por sobrepasar el límite de tolerancia de sales e intoxicar el suelo [24]. Los resultados indican que en el agua evaluada del lago hay condiciones que afectan tanto la fisiología de $H$. viridissima como de L. sativa, por lo que señalan una posible afectación tanto al componente animal acuático como vegetal del lago y sus zonas de influencia, sobre todo, en los vegetales que se riegan después de la descarga del lago. 


\section{Escenarios del lago con respecto al comportamiento de sales}

\section{Escenarios en condición húmeda (mayores precipitaciones)}

Con procesos como la difusión, comúnmente, se establece que el movimiento de las partículas es de áreas de mayor concentración a áreas de menor concentración; los científicos se refieren a esto como una "caminata aleatoria de partículas", donde las moléculas no se mueven en líneas rectas de un punto $\left(\mathrm{X}_{1}\right)$ a punto un $\left(\mathrm{X}_{2}\right)$, sino que interactúan con sus alrededores, chocando y asociándose con moléculas que se encuentran en el camino y asimismo interactúan con el medio donde se mueven [25]. Esto explica la manera en que las aguas ricas en sales y material iónico que ingresan al lago Sochagota tienden a homogenizarse y variar ligeramente sus concentraciones en todo el cuerpo de agua.

Para este escenario de mayores precipitaciones, se tomó en cuenta la condición durante el segundo muestreo, primeros días de junio, que precede a meses con mayores precipitaciones. Bajo esta condición, el lago presenta un aumento en el ingreso de caudal proveniente del sistema quebrada Honda-río Salitre, además de la apertura de la compuerta que regula el sistema, lo cual generó una renovación en la calidad de las aguas pocos días antes.

Inicialmente, se evaluó un escenario diario, donde puede verse que la variable salinidad tiende a normalizarse en la mayor parte del espejo de agua. Este efecto se verificó con los datos del segundo muestreo, para cada punto de interés del cuerpo de agua. Las figuras 11-12 permiten visualizar los resultados de las simulaciones en $t=0$ (recuadros pequeños) y el final ( $t=24$ horas, y $t=1$ mes) de cada escenario.

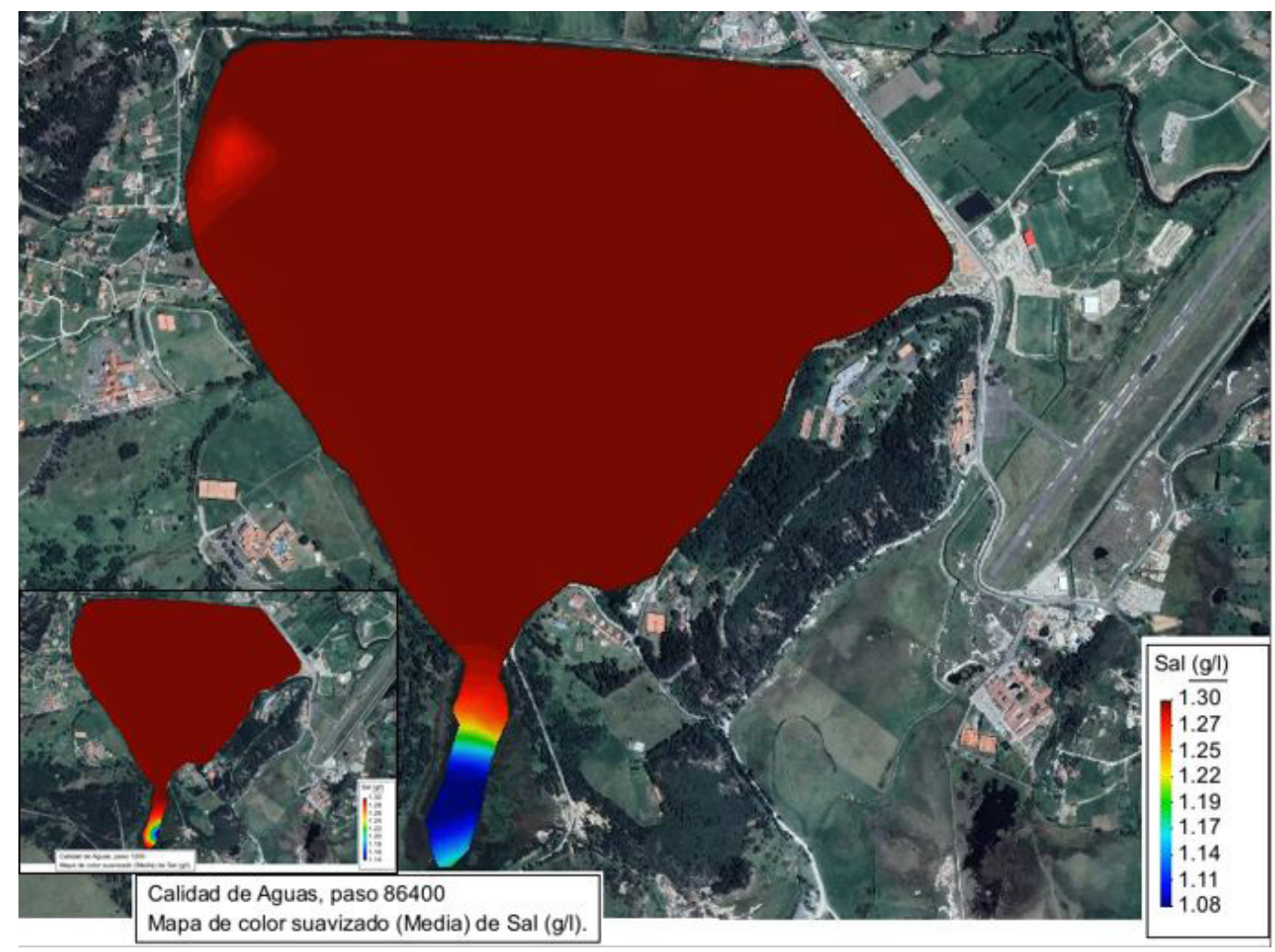

Figura 11. Escenario 1, comportamiento de sales durante las primeras 24 horas, en el periodo de condición húmeda (mayores precipitaciones).

Fuente: elaboración propia. 
A pesar de que en este escenario (figura 11) se reflejan valores estables de salinidad, inferiores a $1530 \mathrm{mg} / \mathrm{l}$, máximo reporte en el lago para el segundo muestreo (tabla 3); en relación con la condición de contorno de salinidad de cada escenario (valor mínimo de salinidad del medio que se debe dar a cada modelo), se toma el promedio de los valores reportados para los puntos muestreados correspondientes al cuerpo de agua.

De la figura 11 se deduce que, a las 24 horas, dada la morfología del lago y las bajas velocidades de flujo, las concentraciones de sales serán las mismas en la entrada del lago que las del sistema quebrada Honda-río Salitre; mientras las concentraciones se normalizan en valores cercanos para el resto del cuerpo de agua.

El lago tiende a tomar las características fisicoquímicas que trae el agua del sistema quebrada Honda-río Salitre. Con valores de salinidad que fluctúan entre $1,83 \mathrm{~g} / \mathrm{l}$ hasta los $1,89 \mathrm{~g} / \mathrm{l}$, (figura 12). Se considera que, en general para condiciones húmedas, con los datos reportados y los obtenidos en los muestreos, la condición del lago se clasifica como holigohalina.

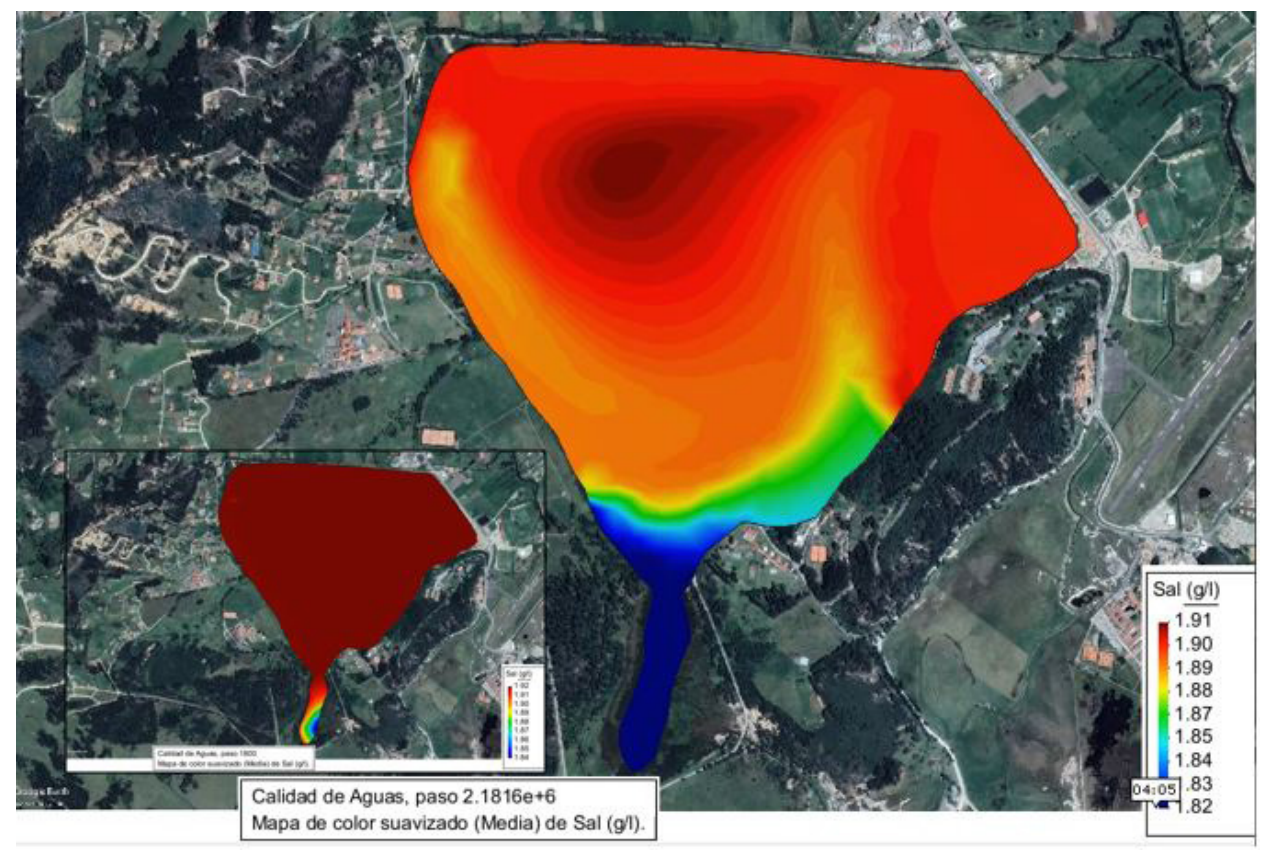

Figura 12. Escenario 2 del comportamiento de las sales a nivel mensual, durante una condición húmeda (mayores precipitaciones).

Fuente: elaboración propia.

\section{Escenarios en condición seca (menores precipitaciones)}

En estos escenarios, se evidencia poco ingreso de caudal proveniente del río Salitre, hecho atribuido a las bajas precipitaciones en la región durante el cuarto muestreo, septiembre del año 2019, que precedió a meses secos. Durante las primeras 24 horas (figura 13), se observa a la entrada de lago aguas provenientes del sistema quebrada Honda-río Salitre con cargas muy salinas con valor de $4,5 \mathrm{~g} / \mathrm{l}$.
Mientras para el resto del lago, los valores oscilan entre los 2,6 g/l y 2,3 g/l.

En la entrada principal del ecosistema, existen afloramientos que pueden identificarse fácilmente con respecto al cuerpo de agua, lo cual puede ser causante de ese aumento en la entrada. Este aumento tiende acumularse en esta zona y, con la disminución del espejo de agua, se genera una costra salina por pérdida de agua por evaporación y bajas precipitaciones. 
La mancha azul de las figuras 13-14 indica la entrada de aguas por el ducto transverso, provenientes del río Chicamocha, ducto que entró en operación desde 2016, ingresando aguas de baja salinidad. Esta zona presentó CE de 2800-2600 $\mu \mathrm{S} / \mathrm{cm}$, para el cuarto escenario, ya el cuerpo de agua presenta mayor concentración, y tiende a normalizar las concentraciones, al igual que lo reportado en campo (punto 5 de muestreo); entretanto, la variabilidad en cuanto a las demás zonas del lago para las concentraciones de CE no fue significativa, durante todas las salidas de campo.

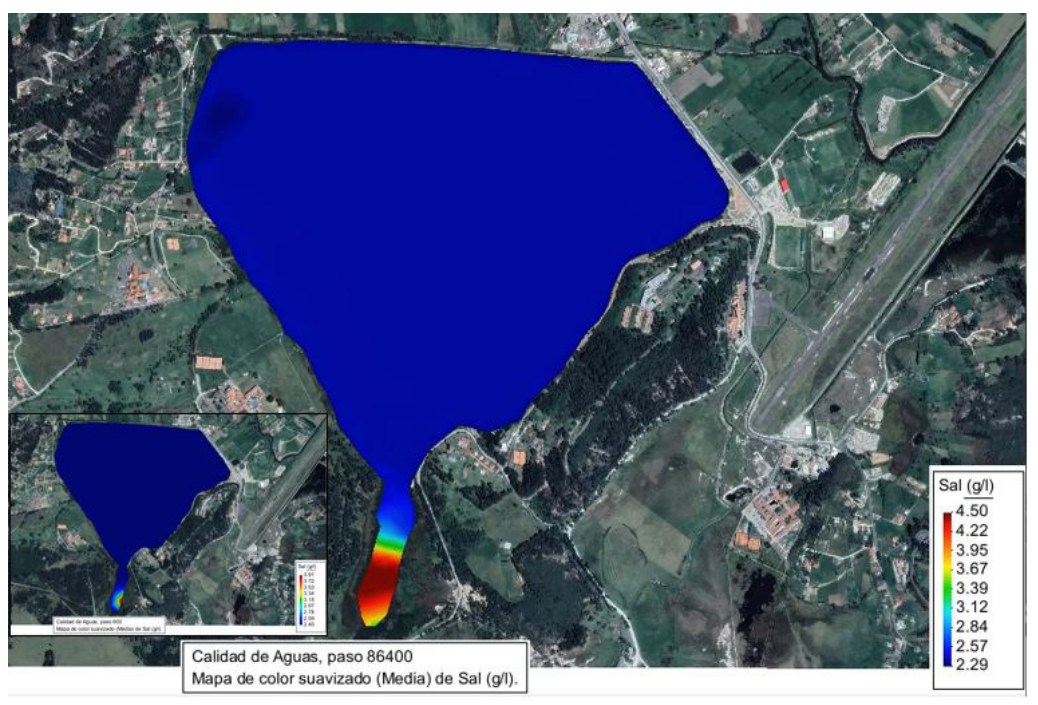

Figura 13. Escenario 3, comportamiento de sales durante las primeras 24 horas, en el periodo de condición seca (menores precipitaciones).

Fuente: elaboración propia.

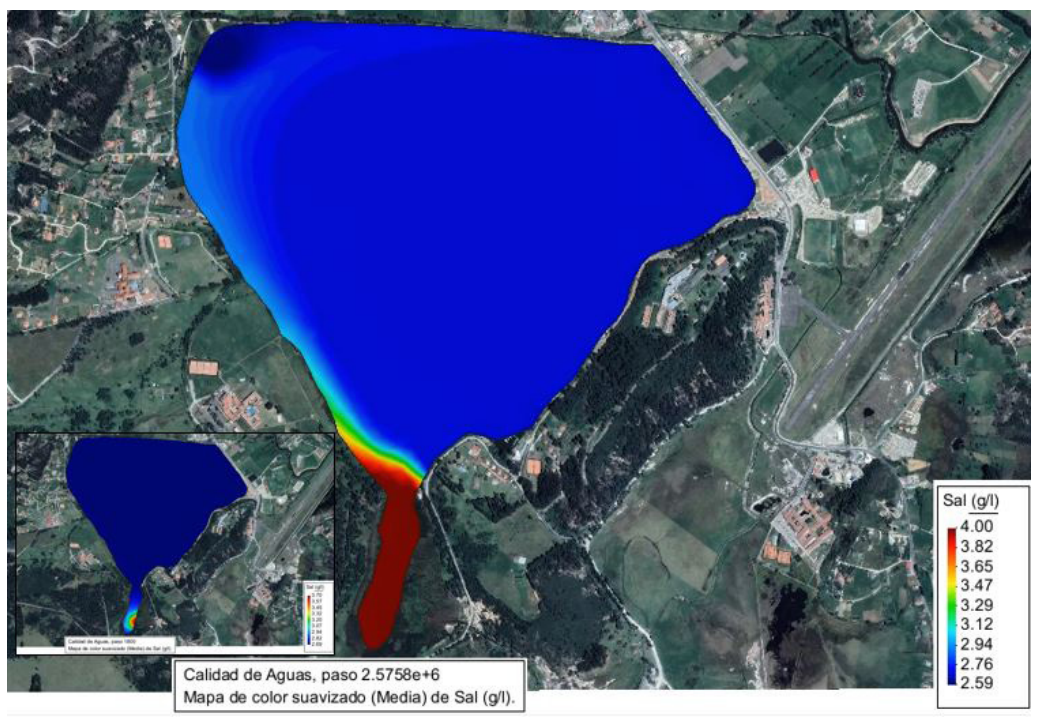

Figura 14. Escenario 4, comportamiento de las sales a nivel mensual, durante una condición seca (menores precipitaciones).

Fuente: elaboración propia. 
Los datos obtenidos por las simulaciones permiten dilucidar que el cuerpo de agua tiende a salinizarse, dependiendo del contenido salino de las aguas que entran al lago y las mayores las concentraciones se encuentran en los periodos secos y de bajas precipitaciones. La medida de mitigación del riesgo requiere la evacuación de aguas que ya han hecho tránsito por el lago, para facilitar la renovación de la calidad de las aguas, como medida más próxima para evitar estados de emergencia en el ecosistema.

\section{Conclusiones}

Mediante el bioensayo de Lactuca sativa, organismo modelo para evaluar fitotoxicidad, se evidenciaron efectos ecotoxicológicos en cuanto a inhibición del crecimiento de tallo y raíz. Las respuestas son más claras para la inhibición del crecimiento de la última, en todos los muestreos y todos los puntos, por las aguas de este sistema y las pertenecientes al sistema quebrada Honda-río Salitre. Se evidencian mayores efectos negativos asociados al uso de estas aguas como fuente para riego, en épocas de baja precipitación, y podría darse una potencial afectación a las raíces de cultivos de la zona y afectaciones a la química de los suelos aledaños.

Con la aplicación de los ensayos de ecotoxicidad con una especie nativa (Hydra viridissima) como organismo modelo, pudieron evidenciarse efectos subletales, siendo una constante en todos los muestreos y todos los puntos. Principalmente, se registraron efectos letales por las aguas pertenecientes a quebrada Honda-río Salitre, en los muestreos 4 y 5. Se resalta que este trabajo es el primero en hacer seguimiento de las afectaciones en la biodiversidad acuática de la zona por las oscilaciones de salinidad, asociada con cambios en los patrones hidroclimatológicos locales.

El uso del modelo 2D Iber fue ideal al caso de estudio, debido a la baja profundidad del lago y a que se hicieron equivalentes datos de conductividad a la salinidad, en los que las magnitudes de sales resultaron más contrastantes con las condiciones hidroclimatológicas regionales (altas y bajas precipitaciones), como lo visualizado en cada escenario mensual y diario.

Las simulaciones atendieron a los datos reportados en las salidas de campo y la incertidumbre de las concentraciones de salinidad, en relación con los puntos evaluados, no presentó diferencias significativas. La salinidad de los escenarios diarios modelados tuvo un coeficiente de variación del $7 \%$, con respecto a los datos de la estación de monitoreo de calidad de agua (reporta datos cada 24 horas), ubicada en el punto de mezcla (punto 6). De esta manera, se da veracidad a escenarios a futuros con las condiciones que pueden presentarse en el hidrosistema.

Los fenómenos como la variabilidad climática impactarán de manera más directa en los lagos someros, con sensibilidad a la salinidad como el lago Sochagota. Por ello es importante haber evidenciado que este lago es salino, independientemente de la condición hidroclimatológica. Sin embargo, sus características se ven influenciadas por las aguas del sistema quebrada Honda-río Salitre y de la condición de operación y el régimen hidrológico, que hacen fluctuar los valores siempre por encima de $1500 \mu \mathrm{S} / \mathrm{cm}$, de modo que se caracteriza siempre como un sistema halino y llega a considerarse mesohalino (concentraciones mayores a $4500 \mu \mathrm{S} / \mathrm{cm}$ ) cuando las condiciones del sistema lo propician.

De acuerdo con las modelaciones de periodicidad diaria, validadas mediante los datos tomados in situ, se verificó que el movimiento de las sales en el lago es un proceso muy uniforme, que evidencia dos comportamientos típicos. El primero, en la entrada al sistema con mayores concentraciones de salinidad; y para el resto del cuerpo de agua, con menor magnitud, siempre conservando uniformidad en las dos zonas descritas. Ello demuestra que, a partir de datos de entrada, las simulaciones representan la realidad del comportamiento de esta variable en el sistema.

El conocimiento de tales correlaciones puede contribuir a mejorar la previsibilidad en la gestión del sistema y de los riesgos que impliquen cambios en las actividades antropogénicas realizadas en el lago. Así también, facilita la generación de planes de que contribuyan a proteger y conservar el lago; además de repensar la disponibilidad de agua dulce a futuro, ya que usar agua del río Chicamocha para mantener su nivel implica modificaciones importantes en el contenido salino que, al retornar a él por medio de distrito de riego, puede comprometer los otros usos. 


\section{Referencias}

[1] A C. Valero, Exploración y evaluación de los recursos geotérmicos: control de calidad de los análisis químicos de manantiales termales de Paipa. Bogotá: Ingeominas Subdirección Recursos del Subsuelo, 2001.

[2] Consejo del Municipio de Paipa, "Plan de Ordenamiento Territorial del municipio de Paipa del 2000”, 2000 [En línea]. Disponible en https://repositoriocdim.esap. edu.co/bitstream/handle/123456789/9867/3223-1. pdf?sequence $=1 \&$ is Allowed $=y \quad$ [accedido: 07-May2020].

[3] Corporación Autónoma Regional de Boyacá Corpoboyacá, "Acuerdo No. $003 \quad 31$ de enero del 2019” 2019 [en línea]. Disponible en: http:// www.corpoboyaca.gov.co/cms/wp-content/ uploads/2019/02/acuerdo-0003-2019.pdf [Accedido: 09-May-2020].

[4] I. Torres, G. Reyes y D. Moreno, “Determinación de sales solubles predominantes en suelos del distrito de riego Alto Chicamocha de Boyacá", Revista Facultad Nacional de Agronomía, vol. 71, n. ${ }^{\circ}$ 3, pp. 4-10, 2018. Doi: http://dx.doi.org/10.15446/rfnam.v71n3.72375

[5] "The Venice System for the Classification of Marine Waters According to Salinity", Limnology and Oceanography, vol. 3, n. ${ }^{\circ}$ 3, pp. 346-347, 1958. Doi: https:// doi.org/10.4319/lo.1958.3.3.0346

[6] A. R. Calderero, Influencia de la temperatura y la salinidad sobre el crecimiento y consumo de oxígeno de la dorada Sparus aurata, Tesis doctoral, Departamento de Biología Animal, Universidad de Barcelona, Barcelona, España, 2001.

[7] Instituto de Hidrología, Meteorología y Estudios Ambientales -Ideam. "Características de las principales ciudades del país”, 1999 [En línea], Ideam.gov.co. Disponible en https://bit.ly/3nUG6qS [Accedido: 15-May2019].

[8] G. Poveda, D. M. Álvarez y Ó. A. Rueda, "Hydro-climatic Variability over the Andes of Colombia Associated with ENSO. A Review of Climatic Processes and Their Impact on One of the Earth's Most Important Biodiversity Hotspots" Clim. Dyn. vol. 36, pp. 2233-2249, 2011. Doi: https://doi.org/10.1007/s00382-010-0931-y

[9] G. Escolano, E. Conde, A. Bockelmann-Evans y B. Ahmadian, "IberWQ -New Simulation Tool for 2D Water Quality Modelling in Rivers and Shallow Estuaries", Journal of Hydroinformatics, vol. 18, n. ${ }^{\circ}$ 5, pp. 816-830, 2016. Doi: https://doi.org/10.2166/hydro.2016.235

[10] M. C. Díaz, M. Bustos y A.J. Espinosa, Pruebas de toxicidad acuática. Fundamentos y métodos. Bogotá: Unibiblos, 2004.
[11] R. Barco y A. Mendez, Identificación de las características hidrológicas y sanitarias del lago Sochagota y de fuentes de agua termomineral en el municipio de Paipa, Boyacá, Tesis de grado, Facultad de Ingenierías Fisicoquímicas, Universidad Industrial de Santander, Bucaramanga, 2010.

[12] A. Villavicencio y A. Villablanca, "Métodos de aforos de caudal”, 2010 [En línea], Informativo Inia-Ururi. Disponible en https://bit.ly/3tuT5AL [Accedido: 07May-0020].

[13] MQuant, "Método volumétrico según Winkler, con pipeta volumétrica”, 2006 [En línea], Water, Food \& Environmental Analytics - Test Kits, Instruments and Accessories (Merck).

[14] Instituto de Hidrología, Meteorología y Estudios Ambientales -Ideam, Protocolos para el monitoreo y seguimiento del agua. Bogotá: autor. Disponible en https:// bit.ly/3vMN16Q [Accedido: 05-May-2020].

[15] IberAula.es, "Manual de referencia de modelación hidrodinámica 2014. Modelización bidimensional del flujo en lámina libre en aguas poco profundas", s.f. [En línea]. Disponible en https://www.iberaula.es/54/ iber-model/downloads [Accedido: 25-May-2020].

[16] Corporación Autónoma Regional de Boyacá -Corpoboyacá, "Plan de ordenación y manejo ambiental de la cuenca alta del río Chicamocha. Diagnóstico. Capítulo I”, 2006 [En línea]. Disponible en https://www. corpoboyaca.gov.co/ventanilla/pomca-cuenca-alta-del-río-chicamocha/ [Accedido: 25-Mayo-2020].

[17] Corporación Autónoma de Boyacá -Corpoboyaca. Subdirección de Recursos Naturales. "Datos de conductividad eléctrica para el lago Sochagota”, 2019 [datos no publicados], solicitados a través de https://www. corpoboyaca.gov.co/ventanilla-atencion/ (de radicado el 05 de septiembre del 2019).

[18] Red Vital SA, "Paipa Boyacá emergencia ambiental lago Sochagota”, 2016 [En línea]. Disponible en https:// slideplayer.es/slide/11736502/ [Accedido: 27-May2020].

[19] El Tiempo, “¿Qué es lo que sucede con el lago Sochagota?”, 2016 [En línea]. Disponible en https://www. eltiempo.com/archivo/documento/CMS-16500623 [Accedido: 05-May-2020].

[20] Instituto Nacional de los Recursos Naturales Renovables y del Ambiente -Inderena, Análisis sobre los efectos causados con la introducción de especies exóticas al medio acuático de Colombia, Bogotá: autor, 1984. Disponible en https://bit.ly/3nU8UzK [Accedido: 05May-2020]. 
[21] R. E. Menzer, M. A. Lewis y A. Fairbrother, "Métodos en toxicología ambiental", en Principles and methods of toxicology, W. Hayes (Ed), 3. ${ }^{a}$ Ed. Nueva York: Haven Press Ltd, 1993, pp. 1391-1418, 1993.

[22] C. E. Castro et al. Protocolo de degradación de suelos y tierras por salinización. Bogota: Instituto Colombiano Agustín Codazzi -Igac, 2012.

[23] G. Fipps, "Irrigation Water Quality Standards and Salinity Management Strategies", Texas Agicultural Extensión Service [En línea] 1996. Disponible en https://oaktrust.library.tamu.edu/bitstream/handle/1969.1/87829/pdf_94.pdf?seq [Accedido: 27-May2020].
[24] I. Walteros, G. Cely y D. Moreno, "Geology and Geomorphology.Formulation of the Management Plan and Environmental Management of the Alta Chicamocha River Basin", Revista Facultad Nacional de Agronomía, vol. 71, n. 3, pp. 8581-8592, 2018. Doi: http://dx.doi. org/10.15446/rfnam.v71n3.72375

[25] E. L. Cussler, Diffusion: Mass Transfer in Fluid Systems, 2. ${ }^{\text {a }}$ ed. Nueva York: Cambridge University Press. 